\title{
The Reception Context of Self-knowledge Notion in Brazilian Educational Researches
}

\author{
Jonathas Gomes Moraes* \\ Postgraduate Program in Education, University of the Southwest Bahia, Vitória da Conquista, Brazil \\ *Corresponding author: jonathasmoraes19@gmail.com
}

\begin{abstract}
This article aim to present the context of reception of a self - knowledge notion by the Brazilian educational field. What was delimited in the purposes of this analysis was the effect of the migration of an idea between distinct contexts, without the proper theoretical treatment that justified the adoption of the idea by the new context. Thus, we use as data collection some researches carried out in the country at the postgraduate level, in which the subject of self-knowledge was addressed, trying to identify the justifications and the forms of signification for adopting that idea. As a result, using Discourse Analysis, one can see from the enunciates described that the forms of meaning of the self-knowledge notion used by research resemble the prescriptive ways in which self-help literatures have historically used this notion to reach their readership. Therefore, the indication suggests certain techniques to be used by the subjectivities put in the game of the significant relation and meaning, for a supposed dominion of itself.
\end{abstract}

Keywords: reception context, self-knowledge, educational field

Cite This Article: Jonathas Gomes Moraes, "The Reception Context of Self-knowledge Notion in Brazilian Educational Researches." American Journal of Educational Research, vol. 5, no. 7 (2017): 776-781. doi: 10.12691/education-5-7-13.

\section{Introduction}

When we assume a notion of self-knowledge as our object of study, we begin to identify it in face of a profuse social condition in meeting needs and uncontrolled pursuit sense of self.

In this way, the present article aims to present part of a discussion made in Master's Dissertation, where the reception context of self - knowledge notion by the Brazilian educational field was approached. We tried to identify, within this perspective, the justifications adopted by some researchers (from academic works at the postgraduate level) in front of: what lead up them to assume a notion of self-knowledge in the scope of their researches and on which forms of signification?

What we sought to understand was the migration effects of the self-knowledge idea, from a possible context of origin $^{1}$ to another distant context, this being the reception context. This proposition is very inspired by the ideas internationalization process and discursive conditions, that tend to favor the circulation of ideas in the educational field. Recognizing this meaning, the displacing process of

\footnotetext{
${ }^{1}$ For this issue of the origin context, the discussion of a possible emergence of the self-knowledge notion from Western philosophical thought is also presented in the Dissertation. We began to consider from the Classical Antiquity initiated by Socrates, by the aphorism knows thyself; it is possibly assumes a condition of beatitude for the knowledge of God in St. Augustine; Passes through the sieve of access to rationality in Descartes; and then to assume a notion of interiority in John Locke, which is configured from what we have closest in the contemporary about a self-knowledge notion.
}

an idea between distinct contexts does not occur without taking the risk of the idea receiving distant meanings from those conceptualized in the origin context $[1,4]$.

Since then, we have realized that the self-knowledge notion has been appropriated by the Brazilian educational field, which has assumed it over certain forms of signification that are propositional to the teacher's formation and practice; close to the forms of signification what Foucault [6] discusses about the positivity's mobilized to subject certain modes of subjectivities under the aegis of supposed techniques for self-control, with brands since Antiquity.

When we look more closely at the supposed techniques employed for self-control, we observe a proximity to certain mediating mechanisms of precarious access to subjectivities, often close to the prescriptive forms used by self-help literatures.

Thus, in view of the signification forms in which a selfknowledge notion is sometimes evoked to satisfy this mediation in the present situation of societies, given to the volubility of meanings and values - an affirmative condition of attending to the self intimacy - which is possible to be provoked together with what is discussed about individualism and narcissism in contemporary societies, something that is seen as unprecedented in the history of humanity $[9,10]$.

In order to confront our data, in view of these perspectives, we assume the Michel Foucault Discourse Analysis's as a proposal to perceive the statements inscribed in the discursive formation of self-knowledge in the analyzed studies. Having as enunciatively field the reception context of a self-knowledge notion in the 
Brazilian educational field - with the statements inscribed in the analyzed researches - we can identify the justifications for the adoption of the notion as discourse capable of favoring the belief in positivity for the teacher's practice.

Thus, the presentation of the following text will be divided into three moments. In the first moment we will contextualize the possible social conditions in which the needs of the self are inserted in an individualistic culture increasingly evidenced. In the second moment we will discuss the possible conditions that favor the reception context of ideas by the educational field, as well the implications of this question for the teacher's practice. In the third moment our analysis will be approached about how the self-knowledge notion is received by the Brazilian educational field, presenting the set of statements identified in some of the academic papers analyzed and, therefore, it was possible to identify the forms of signification and the justification for the adoption of this notion in the scope of researches.

\section{The Context of Individualism in Contemporary Society}

We assume the context of individualism as an extreme condition that pervades among the individuals of contemporary societies and, therefore, capable of favoring the narcissistic cultivation of the self. Believing that this aspect can be seen as unprecedented in the history of humanity, where the search for a self-knowledge notion gains notorious status, reinforced by almost uncontested common sense, both in literary and practical terms ${ }^{2}$.

Along these lines, we bring up Foucault's [7] question of how the subject may have become an object of knowledge that is possible, desirable or even indispensable. This perspective is an invitation to look at the constitutions of what they call self-existing techniques in every civilization, as presupposed, or prescriptions, to individuals in order to fix their identity, to maintain it, or to transform it in function of certain purposes.

Analyzing the supposed techniques that presuppose prescriptions to individuals, we were motivated to look more closely at what is proposed by self-help literatures. We identify in these, a model of literature devoid of internal values, which uses prescriptive techniques as successful formulas, so that people may supposedly reconstitute their self in a reflexive way, engaged in selfrealization and self-enjoyment of the personality for the conduct of life [14].

The emergence of self-help literatures, with their prescriptive formulas, is proposed to enable the subjects to this life-conducting condition, presenting numerous models and training programs since the beginning of the XX century [14], in many of his assaults the selfknowledge notion is enunciated.

As a consequence of this argument, we look at the Modernity project that, throughout the XX century, finds itself in a conflicting transition between modern and postmodern conditions. A fickle subject is exposed in this conflict to meet the needs of identity and image, and highly competitive individualisms in contemporary societies.

\footnotetext{
${ }^{2}$ Read therapeutic terms.
}

We can perceive this from Santos [15], when analyzing the project of Modernity; he sees it as an obsolete project for not having fulfilled some of its promises and others in excess (appearing the expectation that would be overcome in Post Modernity). This conflicting condition derives largely from the modes of capitalism production, which places the contemporary society in a cultural paradigm and this transitional situation is responsible for the present condition of superficiality, such as a void or a deep cultural crisis.

This socio-cultural state of Modernity, which has been creeps since the XVIII century, is justified by the fact that the projects of society focused on the pillars of Regulation and Emancipation3. We emphasize one principles of the Emancipation's pillar - the cognitive-instrumental principle - which in turn articulates with one of the Regulation's pillar principles, the Market's principles, central to the development of individuality ideas and competition, having science and technique as productive forces. These principles would be linked to the promises in excesses of the Modernity project, in the attempt to achieve practical objectives of global rationalization of individual and collective life, coinciding with the capitalism emergency [15].

In this scenario that we still find today, of extensive productions linked to these principles of meeting the identity and individuality needs, we can think about the project of individual in front of this scenario.

The project of individuals we can perceive is that evidenced by the self-image cultivation exaggerated, adapted to the different demands of the contemporary society and affection to the subjectivity access. This new phase of Western individualism is simultaneously linked to a new form of behavioral control and a lifestyles diversification, beliefs and acting ways [10].

This condition is seen as a reshaping of the sectors of contemporary social life, as democratic societies develop way. Thus, a personalization process takes place, which in a comparative and historical perspective, refers to a disruption in the disciplinary process of society. As a new way for society to organize and orient itself, presenting behavior based on consumption and stimulating needs. This process legitimizes individualism in contemporary societies, which are seen as indifference and emptiness [10].

Lipovetsky [10] by the way, tries to situate this issue in a conflicting relationship, between ideologically understanding the condition of societies (he calls a modernist-framework and which could be in transition to the postmodernist condition), and justify a wave of profound changes in social behavior. In fact, it affirms our more flexible condition to the new tendencies, the adoption to a culture of the personality, the cult and rediscovery of the body and its subjective powers. This tendency is exacerbated by a contemporary nonsense movement, which is - devoid of meaning or coherence -

\footnotetext{
${ }^{3}$ The pillars of Regulation and Emancipation are constituted with three principles each: in the pillar of Regulation are the principles of the State, Market and the Community. In the pillar of Emancipation are constituted three logics of rationality, the aesthetic-expressive, the moral-practical and the cognitive-instrumental. Each of these principles is grounded in different philosophical formulations, but they correspond in some way to guide the practical citizen's life (ibid.).
} 
appeal imperative of personalization, in a sense in which individuals perceive object/subject of themselves, stimulated by self-reflection, as is the triggering of contemporary narcissism.

On the topic of contemporary narcissism, Lasch [9] contributes to this discussion by denouncing a social phenomenon called the culture of narcissism, where the conceptions of the world created by society encourage a counteroffensive of the self, collaborating to dilute the boundaries between the individual and his means. He assumed that the political crisis of capitalism would reflect on a general crisis of Western culture, revealing itself as a widespread despair of society for the future and widespread by the misunderstanding of the modern history course. That would be able to trigger a moribund way of life, leading to the end of a war of everything against everything and to competitive individualism.

Thus, from this notion of narcissistic culture, in face of the subject self-filled reality, an excessive preoccupation with the self emerges in the pursuit of happiness and personal achievements. This is accomplished by the contemporary tendency of people, when they feel distressed; they are satisfied with a momentary illusion of personal well-being, health and psychic security. However, the quest for alternative therapies, which seek to generate human potential, only serves to intensify the isolation of the self [9].

Faced with these questions of the individual subjugated to the extreme individualism, and narcissistic cultivation inserted in a state of self protection, to cultivation the selfimage in the social mean - we think the social conditions in which the development of a self-knowledge notion can favor the stimulus of access to the subjectivity, meeting certain demands of contemporary society.

In view of these conditions we can to problematize the educational field (specifically in the academic researches) that tends to reflect the image of the teacher-subject, concerned with the subjective questions of the self-image cultivation and a constant personalization, having as presupposition a self-knowledge notion.

\section{The Educational Field and the Reception Context of Ideas}

The understanding which we seek, as a reception context of ideas, is the one capable of identifying the favorable conditions for the migration of ideas between fields other than knowledge, without the proper theoretical treatment that justifies the adoption of the proposed new idea. This condition rests on the researches carried out at the end of the XX century, mainly in the Human Sciences, which the educational field is not indifferent $[1,4]$.

Bourdieu [1] says that the internationalization of ideas - as a process of migration of ideas - is a social condition of the intellectual life between individuals and place of nationalisms and imperialisms. The intellectuals interested in this process sometimes convey certain prejudgments and stereotypes, as well as preconceived ideas, summary and elementary representations, which feed on events of daily life misunderstandings. He further asserts that these aspects can inflict a narcissistic condition on the social relations to which the idea migrated under such pretexts.
With this, we can think a about the conviction in the internationalization of self-knowledge idea for the educational field, reflecting on what Bourdieu [1] speaks of the scientific conviction. With this conviction we are led to believe that we can master certain social mechanisms and thus propose ideas. However, ideas preconceived and given as true. In addition, he proposes that the process of the internationalization of ideas follows certain structural factors, which compromise the idea reception and favors misunderstandings, one of this is the contextual factor.

The impacts of this condition on the knowledge production in the Brazilian educational field in question are perceptible, and it is possible to perceive the way the field comes into the tension point in transition between Modernity and Post-Modernity. The idea that, on the one hand, many believed that with the arrival of "modern times" we would go through a revolution of thought, both in educational research and in ways of educating; on the other hand, so many others criticize the "farce of Modernity" that tends to obscure our understanding in the ways of thinking in the field of Education [8].

Parallel to this clash, Lopes [11] discusses about the socalled post-critical ${ }^{4}$ theories widely dominated in the educational scenario from the twenty-first century in Brazil, raising questions about the effects of appropriation of poststructuralist studies. It assumes that the field is increasingly challenged by the thinking of post-critical reflections, generating what it calls a theoretical hybridism in the search for academic spaces, resorting in this question to a possible deepening of postmodern characteristics.

We are interested in discussing another issue in view of these characteristics that are available to research in the field of education, with brands since the beginning of the XX century; which concerns the provisions in trying to solve the problems of education by assuming the image of the teacher as agent of transformation.

\subsection{The Image of the Teacher in the Reception Context}

According to this historical issue to attempt a transformation from the image of the teacher - is observed that in a given moment the researches are concerned with telling teachers what and how to do; in another moment the teacher's personal experience is valued by the narrative of life itself. What emerges from these research circumstances is an excess of discourse about the teacher; contributing more to the poverty of teachers' practices, than to the legitimating of these professionals as producers of knowledge [4,12].

In the first moment teachers are seen (in the context of their pedagogical practices) under the eyes and judgments of being mere agents of reproduction; which leads to a teacher's identity crisis, lasting until today. The main concern in this matter is to demonstrate how it is possible for the teacher educate and what limitations he must face in the struggle of his teaching task. Operating from that a

\footnotetext{
${ }^{4}$ The author addresses post-critical theories based on the Curriculum in education; however, we realize that the effects are similar for the educational field as a whole.
} 
discursive exhaustion about the teacher's practice and training [13].

In the other perspective of analysis - in a movement contrary to the presented before - Cestari [4] shows that in present times researches with self-affirming biases have emerged, that take as base the valuation of the teachers personal experience. This research model starts to present a belief in the efficacy of the subjects' training by the approximation of research and training, when the subject becomes the object-investigation of oneself. The author presents us with the Research/Formation Movement 5 the affirmative valuation of the autobiographical experience in the formation of the subject professor/researcher. The Movement justifies that the teacher must construct knowledge of himself narrating his own history.

With this, teachers constitute themselves as professionals seen as mere reproducers of existing schemes. Thus, there is a situation of crisis of identity and of teachers' uneasiness, which is placed as subordinated to a supposed obligation of the academic field to reconstruct the identity of these professionals [13].

The expansion of these issues, coupled with the need for more professionalization of the subject and knowledge specialization, leads to a rejection of historical processes by the immediate acceptance of what is offered to the educational field.

In this way, the educational field tries to promote the teacher's reunion with his personal and professional development through techniques, underlined by the dimensions of reflective practice and professional appreciation. Even if for this, the teacher been only a reproducer of ideas and procedures, sometimes elaborated by other professional groups. Such expansion is not alien to the project of rationalizing education, undermining the autonomy of the teachers themselves.

\section{The Reception of Self-knowledge Notion by the Brazilian Educational Field}

In light of these premises annunciated above, we present now our reception context of the self-knowledge notion in the Brazilian educational field, with the teacher's image as a presupposition for the adoption of the idea in the scope of some academic researches.

The discussion about to be demonstrate, was made from the statements identified in the Theses and Dissertations analyzed - when they were related to a self-knowledge notion - being possible to identify the justifications and the forms of signification when adopting the notion for the purposes of the researches.

Therefore, to holder our arguments, we support in Foucault [5] to understanding the self-knowledge notion as the unity - that is part of the plan of a discourse - then

\footnotetext{
5 The author uses this denomination to facilitate reference to the autobiographical researches in his work. The autobiographical researches adopt the research model as a tonic to rescue of the formative experience of the teacher. We approach this proposed analysis, because autobiographical researches sometimes evokes a self-knowledge notion as one of its presuppositions, but it is not the rule in all research of this nature.
}

it was possible to identify the discontinuities of this notion boarded on the field of delimitation enunciatively, in our case the field of teachers practice and training.

What we expected to understand, specifically, was the process of internationalization of the self-knowledge idea in the educational field and on which forms of signification. Remembering that the reception context is the acceptation of the idea, which not is done without assuming the risk of being attributed different meaning from what we can expect of the origin context $[1,4]$.

Then, the papers selected for this moment of analysis were collected from a survey carried out in the CAPES6 journals portal, taking as a temporal cut the works published between the years 2004 to 2015, selecting the more significant works between Theses and Dissertations.

It was adopted as strategy to identify enunciates the description they assuming in the each work analyzed, under the purposes like justifications presents to support a self-knowledge notion. In this way, it was possible, in the wake of the archaeological analysis, the materiality condition of some enunciates formations arranged in the analyzed works.

For example, when enunciates at a given moment seek to associate a self-knowledge notion with expressions of happiness, freedom and personal growth [2]; and in another moment to the expressions of motivations and weaknesses [17].

In this cases, similarly, enunciates are always arranged as if in a set of relations between the adopted signs and the discursive formation, that is, it presupposes a supposed psychic security by using a notion of self-knowledge, in addition to creating possible overcoming of expectations in the subjectivities arranged in this game.

As a consequence of this arrangement between the signs, the enunciates suggest an attempt to relate the experience and the knowledge that can be made of itself; are organized according to some pre-established schemes of a subjective nature; and may still be determinants in the lives of the subjects involved [6].

For this reasoning, Foucault says about the enunciate identification that can be made from the juxtaposition of the signs, as a threshold of enunciate and the signs - "the signs that constitute its elements are forms that are imposed on enunciates and govern them from the inside ". Thus, it refers to the issue of enunciation as an object capable of being produced, manipulated and transformed by individuals into propositional operations, becoming a "subject of appropriation" for certain "fields of use" [5].

We have also identified in some of the papers analyzed the treatment given to self-knowledge that made us think about the identity assumed by enunciates, given a set of certain conditions. As for example, starting from the presuppositions of the self-knowledge as a training to favor the application of a certain experience and practice directed to the teachers, elaborated by the researchers themselves.

It is proposed to these circumstances, self-knowledge as a possible tool for developing skills and abilities, within a context of practices directed to certain types of readings, and the individual would be able to develop an emancipate condition [14].

\footnotetext{
${ }^{6}$ Higher Level Personnel Improvement Coordination.
} 
It is also observed a set of enunciates such as: selfreflection, self-understanding and self-construction [3]. Configuring a role in which enunciates play the creation a field of semantic identity for the enunciatively function using the prefix self - which brings the intention of the discursive formation of the self-knowledge to practical precepts in society.

From these assertions, we can try to analyze the relation of the highlighted expressions, with the discursive formation of self-knowledge, to the set of signs that expressions can carry historically in our society; as a created domain from which the figures intersect indicating the singular place of the subject and his subjectivity, so the discursive formation would occupy a favorable position to reach the purposes put in those works.

For this we join Foucault [6], when he conceptualizes the problematic of the subject as an object of knowledge by self, from historical-social formations. He says that the analysis of the condition of the subject as a desirable object of self-knowledge is possible to respond to a horizon of difficulties, doubts, uncertainties, conflicts and obstacles presented to us by life in society. And this horizon would be defined as practical-theoretical issues, central and determining in the life of action, and thought. $\mathrm{He}$ also expresses that the overcoming of such questions comes to take place before the so-called techniques of self, pressing to the objectives of how to govern - the subject becomes the object of his dominion.

In arriving at this conclusion we observe that the selfknowledge notion, by the way it is proposed in the works analyzed, resembles the prescriptive ways in which selfhelp literatures have historically used this notion to reach their readership.

This is given by Rüdiger [15] in saying that the phenomenon of self-help literatures is based on principles of individuals subjectivities transformation from a textually mediated set of practices so that people can discover supposed inner resources, aiming at a certain individual position above or under mundane, as well the attainment of happiness and the achievement of goals.

The movements made by self-help literatures since the XX century are associated with what calls "true soul engineering companies"; which use the most varied types of media to disseminate successful formulas and have become a worldwide phenomenon. However, it is a model of literature devoid of internal criteria of value and has basically become a phenomenon of capitalist mass culture, able to reshape social patterns and subjugate the processes of subjectivities contained in inventive designs of the human spirit [15]

Faced with this, we look more carefully at one of the questions asked by Foucault [6], when he tries to understand it: "how the experience that one can make of oneself and the knowledge one can make of oneself, and the knowing that we form them, cannot be organized through some schemes, to meet certain needs of the intimacy of the self?"

\section{Conclusion}

Questioning this way, makes us think the result of the reception context analysis of a self-knowledge notion by the Brazilian educational field, as a process dissemination of ideas migrated between different contexts may be occurring, without due theoretical treatment.

In view of this reflection, we seek to dialogue with Gallo [8] when he commenting about the researches in education, he believes that to undo a possible veil over their intermediations, we will turn our attention to one of the central aspects of the Modernity's Project - which is the Epistemological question. Since the production of knowledge in Modernity had the marks of the principles of objectivity and the universality of knowledge, therefore, in order for the knowledge produced to become valid, research in education could not deny such principles.

Moreover, our inclinations in questioning the pretexts of using a self-knowledge notion in the context of propositional researches to the formation and practice of the teacher, assert themselves when certain arguments are made to mobilize the notion as a necessary condition for the individuals to seek the domain of self [6]. When we ask this question about certain performances of contemporary societies, especially, denounced by the appeal to extreme individualism [10] and narcissistic cultures of self-image [9]; we see that this is aligned with a profuse emergency of self-assertive needs and unbridled search for the sense of self. This aspect is unprecedented in the history of humanity [10], where we believe that self-knowledge gains a status of preconceived idea and of undeniable effectiveness reinforced by the predominant common sense in the different ways of approaching the idea.

However, our considerations do not deplete the possibilities of thinking about the condition of selfknowledge for the educational field, especially, to establish itself as a possible parameter of analysis. What we can, in fact, draw from these discussions are reflections for future researches to think about the different social contexts in which certain ideas can be applied and about the appropriate theoretical treatment.

In addition, it is a perspective opening so that criticism is made and considered as a concern among researchers in the educational field, especially when it is done from the reception context of ideas migrated between different contexts.

\section{Acknowledgements}

I thank the Foundation for Research Support of Bahia (Fapesb) for granting a studentship of the Master's degree. I thank Prof. Dr. Luiz Artur dos Santos Cestari for guidance and support throughout the development of all research.

\section{References}

[1] BOURDIEU, P. As condições sociais da circulação internacional das ideias. Enfoques, Rio de Janeiro, v. 1, n. 1, 2002.

[2] Braga, G. P. Vivências de uma prática pedagógica integral na perspectiva espinosana. (Dissertação de Mestrado), Porto Alegre, 2006.

[3] Canever, V. Contribuição do budismo para a autoconstrução do ser humano na perspectiva de uma educação para a inteireza. (Dissertação de Mestrado), Porto Alegre, 2015. 
[4] Cestari, L. A. S. Autobiografias e Formação: A Circulação da Crença Autobiográfica. CRV, Curitiba, 2013.

[5] Foucault, M. Arqueologia do Saber. Forense Universitária, Rio de Janeiro, 2015.

[6] Foucault, M. Tecnologías del yo. Paidós, Barcelona, 1990.

[7] Foucault, M. Resumo dos Cursos do Collège de France: (19701982). Zahar, 1997.

[8] Gallo, S. "Modernidade /Pós-modernidade: tensões e repercussões na produção do conhecimento em educação". Revista Educação e Pesquisa, v. 32, n. 3, p. 551-565, 2006.

[9] Lasch, C. A Cultura do Narcisismo: a vida americana numa era de esperanças em declínio. Imago, Rio de Janeiro, 1983.

[10] Lipovetsky, G. A era do vazio: ensaios sobre o individualismo contemporâneo. Manole, São Paulo, 2005.

[11] Lopes, A. C. Teorias pós-críticas, política e currículo. Educação, sociedade \& culturas, v. 39, n. 39, p. 7-23, 2013.
[12] Nóvoa, A. (org.). Vida de professores. Porto, Porto, 1992.

[13] Nóvoa, A. Relação Escola - Sociedade: novas respostas para velhos problemas. In: Serbino, R. V. et al. (Org.). Formação de professores. Fundação Editora da UNESP, São Paulo, 1998.

[14] Panozzo, N. S. P. Leitura no entrelaçamento de linguagens: literatura infantil, processo educativo e mediação. (Tese de Doutorado), Porto Alegre, 2007.

[15] Rüdiger, Francisco. Literatura de Auto-ajuda e Individualismo: contribuições ao estudo da subjetividade na cultura de massa contemporânea. Ed. Universidade/UFRGS, Porto Alegre, 1996.

[16] Santos, B. S. Pela mão de Alice: o social e o político na pósmodernidade. Cortez, São Paulo, 1997.

[17] Silva, Simone Cristiane Silveira Cintra. Narrativas poéticas autobiográficas:(auto) conhecimento na formação de educadores. (Tese de Doutorado), Unicamp, São Paulo, 2010. 